\title{
A morphological study of the lingula in South Africans in relation to sagittal split osteotomy.
}

SADJ October 2017, Vol 72 no 9 p408 - p412

RE Rikhotso', C Munsamy²

\begin{abstract}
Purpose: To establish the position and shape of the lingula of the mandible in relation to the surrounding anatomical landmarks, data requisite for inferior alveolar nerve blocks and mandibular osteotomies.
\end{abstract}

Methods: Measurements were carried out on 201 sides from 113 adult dry mandibles.

Results: The most common shape of the lingula was truncated, found in $38.8 \%$ of cases, followed by the triangular (30.8\%), nodular (21.4\%) and assimilated (8.9\%) types. The average distances of the tip of the lingula from the anterior border, posterior border and sigmoid notch of the ramus of the mandible were $20.15 \mathrm{~mm}, 16.77 \mathrm{~mm}$ and $16.3 \mathrm{~mm}$ respectively, and, from the mandibular second molar tooth, $33.3 \mathrm{~mm}$. The lingula was above the level of the occlusal plane in $63.7 \%$ of cases, by an average of $6.5 \mathrm{~mm}$.

Conclusion: The position of the lingula has been shown to be related to adjacent anatomical landmarks which may provide useful clinical references. in Lingula is above the level of the occlusal plane by an average distance of 6.5 $\mathrm{mm}$. Truncated type is the most common shape of the lingula $A$ higher position of the lingula may be anticipated in both Class II and III malocclusions.

Keywords: lingula, mandibular foramen, sagittal split osteotomy

\section{INTRODUCTION}

The lingula is defined as a tongue-shaped bony projection on the medial surface of the ramus close to posterior margin of the mandibular foramen. It was first described by Johannes Baptist Spix in 1815, and following his description it was referred to as 'Spix's ossicle or spine..$^{5}$ It lies in close proximity to the mandibular foramen.

1. Risimati Ephraim Rikhotso: BDS, M Dent, FCMFOS (SA) Department of Maxillofacial and Oral Surgery, Wits School of Oral Health Sciences, University of the Witwatersrand, 7 York Road, Parktown, Johannesburg, 2194, South Africa.

2. Clinton Munsamy: BDS, MSC, M Dent (Wits), FCMFOS (SA) Mulbarton Netcare Hospital.

Corresponding author

Risimati Ephraim Rikhotso:

Tel: +27 11717 2130, Fax: 086765 4436. E-mail: erikhotso@gmail.com
The Sagittal Split Ramus Osteotomy (SSRO) involves a horizontal osteotomy on the medial surface of the mandibular ramus, a sagittal osteotomy along the anterior border of the mandibular ramus, and an internal oblique line and a vertical body osteotomy., ${ }^{1,2}$ in important clinical landmark for performing the horizontal ramus osteotomy is the lingula, the cut being made just above it and extending posteriorly in order to minimize damage to the inferior alveolar nerve..$^{1-4}$

Failure to accurately identify the lingula intra-operatively when performing a sagittal split ramus osteotomy can result in a number of complications such as an unfavourable split and transection of the inferior alveolar bundle which results in haemorrhage and damage to the nerves. ${ }^{6-9}$

Both the shape and the position of the lingula on the medial aspect of the ramus of the mandible are highly variable. ${ }^{10-12}$ An accurate knowledge of the anatomy of the medial aspect of the ramus of the mandible is imperative in order to prevent complications associated with sagittal split ramus osteotomies.

In South Africa, no study has been conducted on dry mandibles to evaluate the position of the lingula in relation to surrounding anatomical structures and the lower molar teeth. This study was therefore undertaken to provide clinicians with reliable clinical landmarks when performing surgery on the mandibular ramus as well as to provide insights on the position of the inferior alveolar nerve (IAN), useful when delivering local anaesthesia for various dental procedures.

\section{ETHICAL CONSIDERATIONS}

Approval for the use of the human dry mandibles for research purposes was first obtained from the Department of Anatomy, University of the Witwatersrand and from the Human Research Ethics Committee of South Africa. Ethics reference number- W-CJ-101109-1.

\section{MATERIALS AND METHODS}

A total of 113 adult human dry mandibles were selected from the Raymond Arthur Dart Collection at the Department of Anatomy, University of the Witwatersrand.

\section{Inclusion Criteria}

- Mandibles that were dentate, with dentition up to and including the mandibular second molar tooth. 
- mandibles for which the age, sex and race were known (identified according to the archives of the collection).

\section{Exclusion Criteria}

- mandibles that were edentulous or that exhibited the presence of a bony defect, deformity or evident pathology.

- The jaws of those cases which were included were placed in full occlusion and a record was made of the Angle Classification, namely, Class 1, Class II or Class III.

- Both the right and the left sides were examined, and from the 113 specimens which were accepted, 201 sets of records were taken. In 25 cases, only one side was included, due to the omitted side not meeting the inclusion criteria.

\section{DATA COLLECTION}

A digital sliding calliper was used to obtain linear measurements of the specimens (Mitutoyo R, Japan, capable of measuring to the nearest $0.01 \mathrm{~mm}$ ). All measurements were carried out by the same investigator.

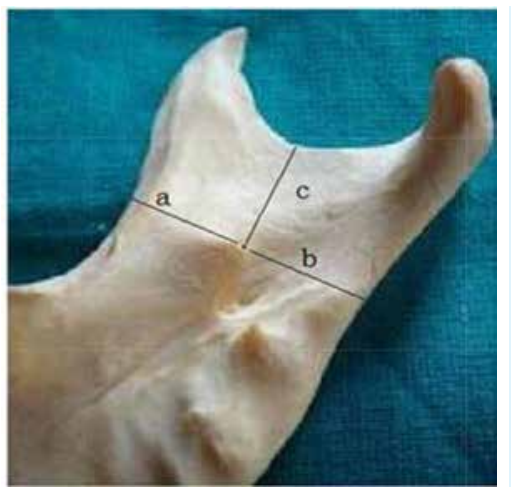

a - distance from the anterior border of the mandible b- distance from the posterior border of the mandible c- distance from the deepest point of the sigmoid notch

Figure 1: Position of the lingula in relation to ramal landmarks

The mandibles were measured according to predetermined points. All measurements were determined to the tip of the lingula (defined as the highest point of the lingula). The following data were obtained:

- Shape of the lingula, defined as truncated, triangular, nodular or assimilated.

- Position of the lingula in relation to ramal landmarks (Figure 1):

A line was drawn from the deepest point of the sigmoid notch to the tip of the lingula ("vertical" line). A line perpendicular to the first line was drawn from the anterior border of the mandible ("horizontal" line).

- The distance of the lingula from the sigmoid notch was determined by measuring the length of the "vertical" line (figure 1, line c).

- The distance of the lingula from anterior border of the ramus of the mandible was measured along that segment of the "horizontal" line (figure 1, line a). The distance of the lingula from the posterior border of the ramus of the mandible was measured along that segment of the "horizontal line" (figure 1, line b).

- Position of the lingula in relation to the mandibular second molar

- The distance was measured from the tip of the distobuccal cusp of the mandibular second molar tooth to the tip of the lingula.

- Position of the lingula in relation to the occlusal plane - A wooden spatula was used to determine the level of the occlusal plane
The lingula was defined as being:

»At the level of the occlusal plane

»Above the occlusal plane

»Below the occlusal plane

The measurements and observations were repeated by the investigator and by an independent observer to enable both intra-observer and inter-observer error tests.

\section{RESULTS}

Of the 113 mandibles, 77 (68\%) were from male individuals and 36 (32\%) were from females. The age at death distribution of the specimens ranged from 20 to 50 years, with a mean of 40.2 years (See Figure 2).

Shape of the lingula

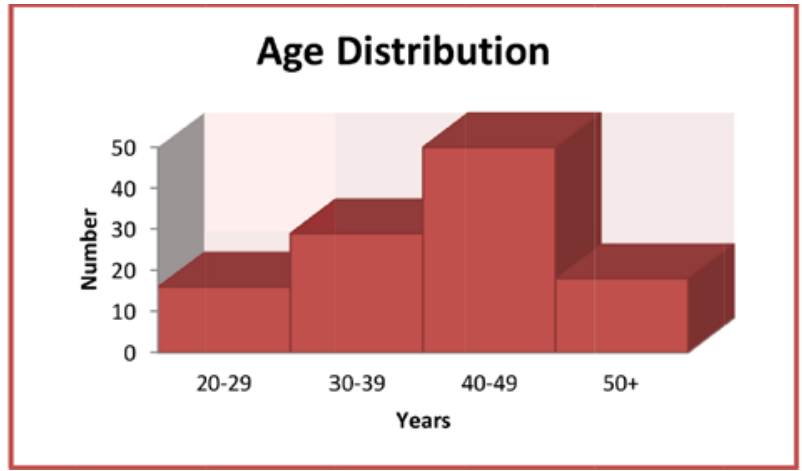

Figure 2: Age at death distribution of specimens.

The most common shape of the lingula noted was the truncated type which was found in $38.8 \%$ of cases, followed by the triangular, nodular and assimilated types which comprised $30.8 \%, 21.4 \%$ and $8.9 \%$ respectively (see Figures 3 and 4). In 26.4\% of cases, there was a difference between the right and left sides of the mandible with respect to lingula shape. The incidence of the truncated and assimilated types in the male and female mandibles was almost equal (see Figure 5). However, the triangular variant was more commonly noted in females, found in $35 \%$ of the cases examined, as compared with $26.4 \%$ in

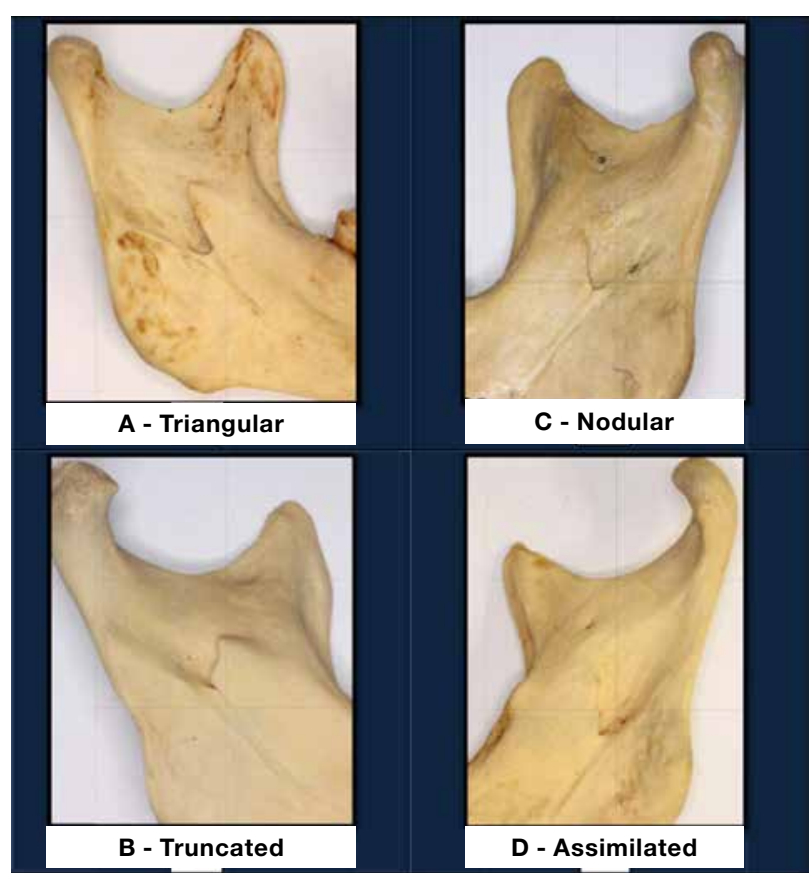

Figure 3: Anatomical variations of the lingula.

A-Triangular B-Truncated C-Nodular D-Assimilated 
Anatomical variations of the lingula

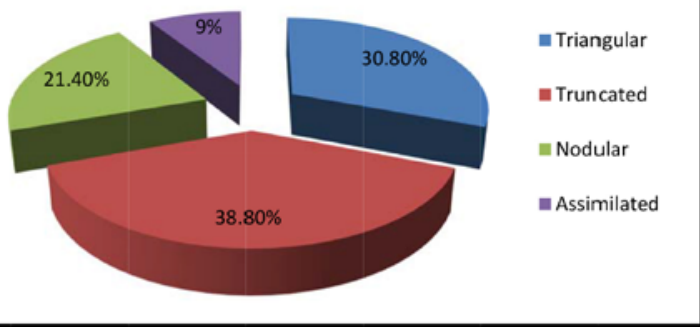

Figure 4: Incidence of the anatomical variations of the lingula

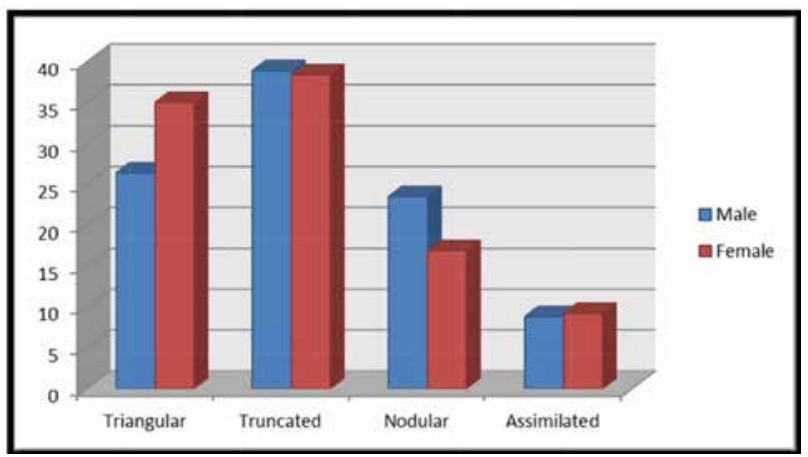

Figure 5: Percentage distribution of anatomical variations of the lingula amongst males and females.

males. The nodular variant was noted more commonly in males $(23.5 \%)$ than in females (16.9\%). The assimilated type was only marginally more common in females with an incidence of $9.2 \%$ as compared with the $8.8 \%$ noted in male mandibles.

Location of the lingula in relation to ramal landmarks and the mandibular 2 nd molar tooth

The position of the lingula in relation to mandibular ramal landmarks is shown in Table 1. There were no statistically significant differences in position of the lingula between the right and left sides of the mandible in terms of the distances from the anterior border, posterior border and sigmoid notch of the ramus of the mandible, with $p=0.18$, 0.83 and 0.2 respectively. Measurements indicated that the average horizontal distance of the lingula from the anterior border of the ramus of the mandible was $20.42 \mathrm{~mm}$ (right) and $19.88 \mathrm{~mm}$ (left), the average horizontal distance from the posterior border of the ramus was $16.77 \mathrm{~mm}$ (right) and $16.84 \mathrm{~mm}$ (left) whilst the average vertical distance of the lingula from the sigmoid notch was $16.53 \mathrm{~mm}$ (right) and $16.1 \mathrm{~mm}$ (left).

The horizontal distance from the tip of the disto-buccal cusp of the mandibular second molar tooth to the tip of the lingula was found to be on average $33.8 \mathrm{~mm}$ (right) and $32.9 \mathrm{~mm}$ (left) (Table 1). This implies that the average distance from the second molar to the posterior border of the ramus of the mandible is approximately $48 \mathrm{~mm}$. There were no statistical differences between the measurements from the right and left sides of the mandible.

The relationship of the lingula to the occlusal plane The relationship between the lingula and the occlusal plane, as found in this study, is depicted in Table 2. No statistically significant difference was observed between the right and left sides of the mandible. In $36.3 \%$ of cases, the lingula was found to be at the level of the occlusal plane. The lingula was above the level of the occlusal plane in $63.7 \%$ of cases, by an average distance of $6.5 \mathrm{~mm}$ (SD $+/-2.42 \mathrm{~mm}$ ) on both the left and right sides of the mandible.

The position of the lingula in relation to the type of occlusion

The lingula was found to be located above the level of the occlusal plane in $70 \%$ of Class 1 occlusions, $65 \%$ of Class 11 occlusions and $58 \%$ of Class III occlusal relationships, with an average distance of $6.1 \mathrm{~mm}(\mathrm{SD}+/-3.46) 7.1 \mathrm{~mm}$ (SD +/- 4.09) and $6.5 \mathrm{~mm}(\mathrm{SD}+/-3.2)$ respectively. The lingula was not seen on any specimen to be below the occlusal plane.

\section{DISCUSSION}

The lingula, as its name implies, is a tongue shaped projection found on the medial aspect of the ramus of the mandible. It overlies the mandibular foramen, where the inferior alveolar vessels and nerve enter into the mandibular canal, and has become an important clinical landmark to surgeons as well as dental practitioners. The lingula is a reliable and useful anatomical landmark in determining the position of the mandibular foramen when performing medial ramus osteotomy. Knowledge of its shape and position is thus invaluable in minimising complications associated with this procedure.

However, there is a paucity of data regarding the shape of the lingula. Nicholson ${ }^{13}$ and Dubrul ${ }^{14}$ acknowledged that various shapes may be present, but failed to describe the variety. Currently, four different shapes are recognised, namely the triangular, truncated, nodular and the assimilated. ${ }^{15-18}$

This study found that the truncated type was the predominant lingula shape noted in $38.8 \%$ of cases, with the triangular type only marginally less common (30.8\%), followed by the nodular (21.4\%) and assimilated (8.9\%) variants. These results are similar to those of studies conducted by Kositbowornchai et al. ${ }^{19}$ and Jansisyanont et al. ${ }^{10}$ who reported the truncated variant to be the most common type, comprising $47 \%$ and $46 \%$ of the specimens respectively. Hossain et al. ${ }^{20}$ only noted three variants of the lingula in his study of 208 Bangladeshi mandibles i.e. triangular, truncated and assimilated comprising $70.2 \%$, $20.2 \%$ and $9.6 \%$ respectively.

The reason for the variation in shape is unknown. Tuli et

Table1: Location of the lingula in relation to ramal landmarks and the mandibular 2nd molar tooth (millimetres)

\begin{tabular}{|c|c|c|c|c|c|c|c|}
\hline \multirow{2}{*}{ Parameter } & \multicolumn{2}{|c|}{ Average } & \multicolumn{2}{|c|}{ Range } & \multicolumn{2}{|c|}{ Standard Deviation } & \multirow{2}{*}{$\begin{array}{c}P \text {-value } \\
\text { (t-test) }\end{array}$} \\
\hline & Right & Left & Right & Left & Right & Left & \\
\hline Distance from the anterior border & 20.42 & 19.88 & 12.98 to 28.08 & 13.09 to 27.72 & 2.85 & 2.84 & $p=0.18$ \\
\hline Distance from the posterior border & 16.77 & 16.84 & 12.18 to 22.05 & 10.73 to 22.77 & 2.05 & 2.2 & $p=0.83$ \\
\hline Distance from the sigmoid notch & 16.53 & 16.1 & 9.25 to 22.74 & 10.33 to 20.65 & 2.56 & 2.2 & $p=0.2$ \\
\hline $\begin{array}{l}\text { Distance of the lingula from the } \\
\text { mandibular } 2 \text { nd molar }\end{array}$ & 33.8 & 32.9 & 26.4 to 42.41 & 20.87 to 40.68 & 3.3 & 3.9 & $p=0.08$ \\
\hline
\end{tabular}


Table 2: The relationship of the lingula to the occlusal plane

\begin{tabular}{|c|c|c|c|c|c|c|c|c|c|}
\hline \multirow[b]{2}{*}{ Occlusal plane } & \multicolumn{2}{|c|}{ Number } & \multicolumn{2}{|c|}{ Range } & \multicolumn{2}{|c|}{ Average } & \multicolumn{2}{|c|}{ Standard Deviation } & \multirow{2}{*}{$\begin{array}{c}p \text {-value } \\
\text { (t-test) }\end{array}$} \\
\hline & Right & Left & Right & Left & Right & Left & Right & Left & \\
\hline At Level & 38 & 35 & - & - & - & - & - & - & \\
\hline Above Level & 68 & 60 & 2.23 to 16.06 & 1.8 to 14.19 & 6.57 & 6.53 & $+/-2.42$ & $+/-2.42$ & $p=0.86$ \\
\hline
\end{tabular}

al. ${ }^{12}$ suggested that the lingula is considered a vestigial structure, serving as a point of attachment for the sphenomandibular ligament (which is considered an accessory ligament of the temporomandibular joint), and that no lengthening or tension is produced on the ligament in all movements of the jaw. It is therefore doubtful

\begin{tabular}{|c|c|c|c|c|c|}
\hline & \multirow{2}{*}{ Number } & \multicolumn{2}{|c|}{$\begin{array}{l}\text { Lingula in relation to } \\
\text { the occlusal plane }\end{array}$} & \multirow{2}{*}{$\begin{array}{c}\text { Average distance } \\
\text { above the } \\
\text { occlusal plane }\end{array}$} & \multirow{2}{*}{$\begin{array}{l}\text { Standard } \\
\text { Deviation }\end{array}$} \\
\hline & & At Level & Above & & \\
\hline Class 1 & 94 & 28 & 66 & $6.1 \mathrm{~mm}$ & 3.46 \\
\hline Class 11 & 29 & 10 & 19 & $7.1 \mathrm{~mm}$ & 4.09 \\
\hline Class 111 & 12 & 5 & 7 & $6.5 \mathrm{~mm}$ & 3.2 \\
\hline
\end{tabular}
as to whether the lingula is disappearing as a process of evolution such as could be suggested in the cases of the nodular and assimilated types. ${ }^{12,19}$ It has been postulated that the lingula, together with other non-metric measurements of the skull, could be used as an anthropological marker to assess different populations and races. ${ }^{12,19,21}$ However, further investigations need to be carried out to confirm this hypothesis.

Results from this study have indicated that the lingula is on average $20.15 \mathrm{~mm}$ (20.42mm [right], $19.88 \mathrm{~mm}$ [left]) from the anterior border of the ramus of the mandible, $16.8 \mathrm{~mm}$ (16.77mm [right], $16.84 \mathrm{~mm}$ [left]) from the posterior border of the ramus of the mandible and $16.3 \mathrm{~mm}$ from the sigmoid notch $(16.53 \mathrm{~mm}$ [right], $16.1 \mathrm{~mm}[\mathrm{left}])$. These results varied only marginally from those reported by Jansisyanont et $\mathrm{al}^{10}$ but exhibited a large discrepancy from the values obtained by $\mathrm{Kim}$ et al. ${ }^{22}$ A possible explanation for the variation in results could be due to different methodology employed by the different investigators. The methodology employed in this study proved to be most reliable and reproducible in determining points of reference for the anatomical location of the lingula, with correlation coefficients of $>95 \%$ in both intra-observer and inter-observer error tests. In addition, it is a simple method that can be used intraoperatively to gauge the probable anatomical position of the lingula.

This study found that the horizontal distance from the tip of the disto-buccal cusp of the mandibular second molar to the tip of the lingula was on average 33mm (SD +/$3.3 \mathrm{~mm})$. There was no statistically significant difference in this measurement between the left and the right sides of the mandible. Kim et al. ${ }^{22}$ in a similar study on Korean mandibles found that the average horizontal distance from the distal side of the mandibular second molar to the lingula tip measured $28.7 \mathrm{~mm}$ (SD +/- 2.87mm). Jansisyanont et al. ${ }^{10}$ in a study conducted on Thai mandibles, found the distance from the lingula tip to the disto-buccal aspect of the second molar tooth to be approximately $29.7 \mathrm{~mm}$ (SD +/- 4.4mm). These studies have shown that a possible difference exists between the anatomical locations of the lingulae amongst different population groups in relation to surrounding landmarks. This may be due to variation in the size of the rami of mandibles, as noted in a study by Lee, ${ }^{23}$ who found that Korean mandibular rami were the largest among Asians, but were smaller than those of Caucasians.

There are few studies in which the position of the lingula

was evaluated with respect to the level of the occlusal plane, $, 0,22$ most having reported rather on the position of the mandibular foramen in relation to the occlusal plane. 13,19,24,25 Whilst anatomical relationships and measurements of the mandibular foramen are invaluable, it is often not easily visualised intraoperatively, and is therefore less likely to be considered a clinical landmark. The lingula, however, can be readily visualised intraoperatively, given of course that the operator has a good understanding of its anatomical location, and therefore is regarded as a better clinical landmark. In this study, results indicated that the lingula was most commonly located above the level of the occlusal plane $(63.7 \%$ of cases), which is a finding similar to those reported in several other studies. ${ }^{10,22}$ Although there were no statistically significant differences in the data between the right and the left sides of the mandible, it is important to note that, in some instances, the level of the lingula in relation to the occlusal plane differed from side to side within the same mandible. The average distance above the level of the occlusal plane was $6.5 \mathrm{~mm}$ (SD $+/-2.42 \mathrm{~mm}$ ), which is higher than that reported by Jansisyanont et al, ${ }^{10}$ who found this measurement to be on average $4.5 \mathrm{~mm}$ (SD +/- 2.6mm) above the level of the occlusal plan. The results from a study conducted in Thailand found that in $80 \%$ of cases, the lingula was located above the level of the occlusal plane, while in $20 \%$ of cases it was located below, and in no incidences was the lingula found to be at the level of the occlusal plane..$^{10}$ In this study, there were no incidences in which the lingula was located below the level of the occlusal plane.

An attempt was also made to identify possible discrepancies in the anatomical position of the lingula that may be related to the type of occlusion. Results indicated that in $70 \%$ of class 1 occlusions, $65 \%$ of class 11 occlusions and $58 \%$ of class III occlusal relationships, the lingula was found to be above the level of the occlusal plane, with average distances of $6.1 \mathrm{~mm}, 7.1 \mathrm{~mm}$ and $6.5 \mathrm{~mm}$ respectively. Thus the highest average position of the lingula was noted in Class II followed by Class III malocclusions. This suggests that a higher position of the lingula should be anticipated in both Class II and Class III malocclusions.

Several studies have found that if the lingula is situated high on the mandibular ramus, the medial horizontal osteotomy is made higher on the mandibular ramus in a thin region where there is little or no cancellous bone. ${ }^{2,26-}$ ${ }^{28}$ According to Cillo and Stella, ${ }^{29}$ the lingula was found in Class III malocclusions to be higher than in Class I and Class II malocclusions, the ramus of the mandible exhibited 
limited marrow and the inferior alveolar nerve was found to be near the inferior border of the mandible. All these factors increase the risk of occurrence of an unfavourable fracture and IAN injury. Class III malocclusions are therefore regarded as having the greatest risk of acquiring an unfavourable fracture, due to the high lingula. ${ }^{29}$

In many measurements a considerable range was recorded. This possible variation should be borne in mind when applying the average data of the position of the lingula.

\section{CONCLUSIONS}

This study has attempted to describe the position and relation of the lingula to adjacent anatomical landmarks. This information could be useful when performing mandibular osteotomies or anaesthetic infiltration in this area. To this end, a simple set of guidelines may be suggested, using a 3-2-1-1 x 16mm rule to help describe the position of the lingula in relation to the surrounding structures:

- $3 \times 16 \mathrm{~mm}=$ the approximate distance from the second molar tooth to the posterior border of the mandible $(48 \mathrm{~mm})$

- $2 \times 16 \mathrm{~mm}=$ the approximate distance from the second molar to the lingula $(32 \mathrm{~mm})$

- $1 \times 16 \mathrm{~mm}=$ the approximate distance from the sigmoid notch to the tip of the lingula $(16 \mathrm{~mm})$

- $1 \times 16 \mathrm{~mm}=$ the approximate distance from the lingula to the posterior border of the mandible $(16 \mathrm{~mm})$

- These standard references may help in the more proficient intraoperative location of the lingula.

\section{References}

1. Epker BN. Modifications in the sagittal osteotomy of the mandible. J Oral Surg , 1977; 5:157-9

2. Smith BR, Rajchel JL, Waite DE, Read L. Mandibular ramus anatomy as it relates to the medial osteotomy of the sagittal split ramus osteotomy. J Oral Maxillofac Surg, 1991; 49:112-6.

3. Hunsuck E. A modified intraoral sagittal splitting technic for correction of mandibular prognathism. J Oral Surg 1968; 26:250-3.

4. Bell WH, Proffit WR, White RP. Surgical Correction of Dentofacial Deformities. Philadelphia: Saunders, 1980:pp 855-901.

5. Dobson J. Anatomical Eponyms, 2nd Ed. Edinburgh, London: E. \& S. Livingstone, 1962:p194.

6. Turvey TA. Intraoperative complications of sagittal osteotomy of the mandibular ramus: Incidence and management. J Oral Maxillofac Surg, 1985; 43:504-9.

7. Chrcanovic B.R, Freire-Maia B. Risk factors and prevention of bad splits during sagittal split osteotomy. Oral Maxillofac Surg, 2012; 16:19-27.

8. Kriwalsky M.S, Maurer P, Veras R.B, Eckert A.W, Schubert J. Risk factors for a bad split during sagittal split osteotomy. Br. J. Oral and Maxillofac Surg, 2008; 46:177-9.

9. Behrman S.J. Complications of sagittal osteotomy of the mandibular ramus. J Oral Surg, 1972; 30:554.

10. Jansisyanont P, Apinhasmit W, Chompoopong S. Shape, height and location of the lingula for sagittal ramus osteotomy in Thai. Clin Anat, 2009; 22:787-93.

11. Murlimanju B.V, Prabhu L.V, Pai M.M, Paul M.T, Saralaya V.V, Kumar C.G. Morphological study of lingula of the mandibles in South Indian population. Morphologie, 2012; 96: 16-20.

12. Tuli A, Choudhry R, Choudhry S, Raheja S, Agarwal S. Variation in shape of the lingula in the adult human mandible. $J$ Anat, 2000; 197:313-7.

13. Nicholson ML. A study of the position of the mandibular foramen in the adult human mandible. Anatomical Record, 1985; 212:1102.

14. Dubrul EL. Sicher and Dubrul's Oral Anatomy. 8th Ed. New York: Ishiyaku Euro America, 1988:pp32-5.

15. Hollinshead WH. Textbook of Anatomy. Calcutta: Harper \&
Row; 1962: pp 855-6.

16. Berkovitz BKB, Holland GR, Moxham BJ. A Colour Atlas \& Textbook of Oral Anatomy. London: Wolfe Medical Publications, 1978:p15.

17. Sampson HW, Montgomery JL, Henryson GL. Atlas of the Human Skull. Texas: Texas A \& M University Press; 1991:pp130-1.

18. Williams PL, Bannister LH, Berry MM, Collins P, Dyson M, Dussek JE, et al. Gray's Anatomy. 38th ed. Edinburgh: Churchill Livingstone, 1995:pp576.

19. Kositbowornchai S, Siritapetawee M, Damrongrungruang T, Khongkankang W, et.al. Shape of the lingula and its localization by panoramic radiograph versus dry mandibular measurement. Surg Radiol Anat, 2007; 29: 689-694

20. Hossain S.M.A, Patwary S.I, Karim M. Variation in shape of the lingulae in the adult human mandibles of Bangladeshi skulls. Pak J Med Sci, 2001;17:233-6.

21. Berry A.C. Factors affecting the incidence of non-metrical skeletal variants. J Anat, 1975; 120: 51935

22. Kim H.J, Lee H.Y, Chung I.H, Cha I.H, Yi C.K. Mandibular anatomy related to sagittal split ramus osteotomy in Koreans. Yonsei Medical Journal, 1997; 38 (1): 19-25.

23. Lee D.S. A study on mandible of Korean. Medical Digest (Korean) 1961,3:971-1005.

24. Monnazzi M.S, Passeri L.A, Gabrielli M.F.R, Bollini P.D.A, de Cavalho W.R.S, da Costa Machodo H. Anatomic study of the mandibular foramen, lingula and antilingula in dry mandibles, and its statistical relationship between the true lingula and the antilingula. Int. J Oral Maxillofac. Surg. 2012; 41: 74-8.

25. Mbajiorgu E.F. A study of the mandibular foramen in adult black Zimbabwean mandibles. Cent Afr J Med, 2000; 46(7): 184-90.

26. De Souza Fernandes AC, Cardosa P.M, Fernandes I.S, de Moraes M. Anatomic study for the horizontal cut of the sagittal split ramus osteotomy. J Oral Maxillofac Surg, 2013; 71: 1239-44.

27. Tom W.K, Martone C.H, Mintz S.M: A study of mandibular ramus anatomy and its significance to sagittal split osteotomy. Int J Oral Maxillofac Surg, 1997; 26: 176-8.

28. Wolford L.M, Benett M.A, Rafferty C.G. Modification of the mandibular ramus sagittal split osteotomy. Oral Surg Oral Med Oral Pathol, 1987; 64:146-55.

29. Cillo J.E. Jr, Stella J.P. Selection of sagittal split ramus osteotomy technique based on skeletal anatomy and planned distal segment movement. Current Therapy, 2005; 63:109-14. 